\title{
Producing virtual reality (VR) field trips - a concept for a sense-based and mindfull geographic education
}

\author{
Katharina Mohring and Nina Brendel \\ Institute of Environmental Science and Geography, University of Potsdam, 14476 Potsdam, Germany \\ Correspondence: Katharina Mohring (kmohring@uni-potsdam.de)
}

Received: 23 April 2020 - Revised: 16 February 2021 - Accepted: 8 June 2021 - Published: 12 August 2021

\begin{abstract}
Virtual reality (VR) enables users to have an alternate reality experience. The virtual world surrounds users and can be perceived atmospherically. However, VR triggers human perception with far-reaching consequences. VR worlds are hardly questioned by the consumers. The effects of virtual experiences could have a lasting impact on learning or acting. Therefore, it is necessary to reflect on the use of VR in educational contexts. In our research and teaching project students produced VR field trips on topics of urban society-environment research. Based on the project findings we explain how we implement VR as a practice of sense-based and content-based acquirement of space and a (visual) practice of mediation. A key element is the critical reflection on the meaning of body and emotion. This can be a way to mindfulness - both in the context of teaching and in the context of the transformation of society-environment relations in general.
\end{abstract}

\section{Introduction}

In recent years, virtual reality (VR) as a new technology has become easily accessible to everyone. It is already used in multiple contexts, for instance in gaming, job training, and increasingly also education. To experience VR, users put on VR glasses and immerse themselves in an alternate reality like a flight through the universe or a walk over an active volcano. It appears as if they are present in a different world and they react similarly to in everyday life - with fear, joy, astonishment, etc. (Slater and Sanchez-Vives, 2016). This is the effect of an atmospheric feeling: users perceive VR as situations and react affectively and emotionally. This effect is powerful. Users hardly question VR environments. The experienced situations trigger learning effects and possibly change behaviour. For geographic education this must be reflected on critically. If people acquire space and content holistically at first, they need a mindset to understand how their body and emotions are part of understanding the virtual world. This is similar to a critical reflection on visual and image-related communication of space (Schlottmann and Miggelbrink, 2015b) but with the difference of a sense-based (more-than-visual but body-related) view VR acquires. But the principle is the same: VR should be treated like images as a practice of acquiring, mediating, and producing space (Schlottmann and Miggelbrink, 2015a:24 f.).

In this paper we discuss how virtual reality can be conceptually integrated into geographical education. Therefore, we suggest using a mindful teaching concept. According to Manemann (2014:77), we refer to, on the one hand, strengthening self-efficacy and, on the other hand, generating attention for things that one does not usually consider. The goal is to stimulate the transformation of the self in the sense that one's own (body-related) needs are discovered and that needs of the environment (other people, nature, things) are understood. This could be a way to encourage mindfulness in general. From this perspective, we deconstruct and reconstruct VR as a spatial construction process (Brendel and Mohring, 2020). We consider two perspectives: first the phenomenological part of reflecting on a sense-based practice of (space) acquirement in VR and second a constructivist part of developing an understanding of content-related and visual practices of mediation (Schlottmann and Miggelbrink, 2015b). We discuss this through our teaching and research project in which students developed VR field trips based on empiric research in the cities of Vienna and Berlin. The research topic refers to temporary urban development and the relation between urban society and environment. The students acted 
as researchers and producers of VR. We empowered them to reflect on the function and meaning of VR within spacerelated learning processes. By means of the project design (as a constructivist research programme according to Hard, 1989, 1995) and three examples, we want to illustrate how a critical reflection on VR could be stimulated (Mohring and Brendel, 2020).

\section{Why does virtual reality make a difference in geographic education?}

VR is a digital form of communication. Like the internet, application programs, or social media tools it is based on simple binary data. In VR, users receive data in an immersive form because visual and acoustic information surrounds them. This is the way VR disseminates information. It does not specify content but provides information in a form that can only be used by standardized routines. In this way, it expands and at the same time restricts how communication serves further communication (Baecker, 2005:178 ff.; Luhmann, 1984:221). In consequence, the primary influence of digital media should be discussed through changing communication processes (Stalder, 2018). In our project, we understand VR as a medium that addresses peoples' ability to perceive. Communication about perceptions always includes a part that cannot be put into language but influences communication itself (Baecker, 2005:190). The question that arises is what difference VR makes through its perceptual proximity - especially in the context of understanding and learning.

\subsection{Technical material description}

VR experience requires an immersive form of technical material condition. Via a head-mounted display (HMD) or phone-based cardboard headset (housing with two lenses in which a smartphone can be placed; see Fig. 1) users can experience a virtual $360^{\circ}$ environment. The head movement is registered via head tracking. Thus, it is possible to see something different in every possible viewing direction. Therefore, the visual representation creates an "illusion of surrounding" (Slater, 2009:3550). Users are brought "into the picture" (see Slater and Wilbur, 1997; Slater, 2009). Within this picture users are able to perform "a walkthrough", i.e. they can apparently cover distances and change directions and perspectives (Chen, 1995:29). By this, the impression of an experienceable space is further strengthened because places can be changed. Figure 2 shows an image sequence in a computer-generated VR (the social VR AltspaceVR): the user moves as an avatar towards a group of other avatars to meet and talk. Figure 3 shows yet another form of presentation. In image-based VR systems, photo-quality panoramic views are used. For this purpose, $360^{\circ}$ or VR cameras are applied to convert natural scenes into digital data. Moving is then achieved by stitching together panoramic images taken from different positions.

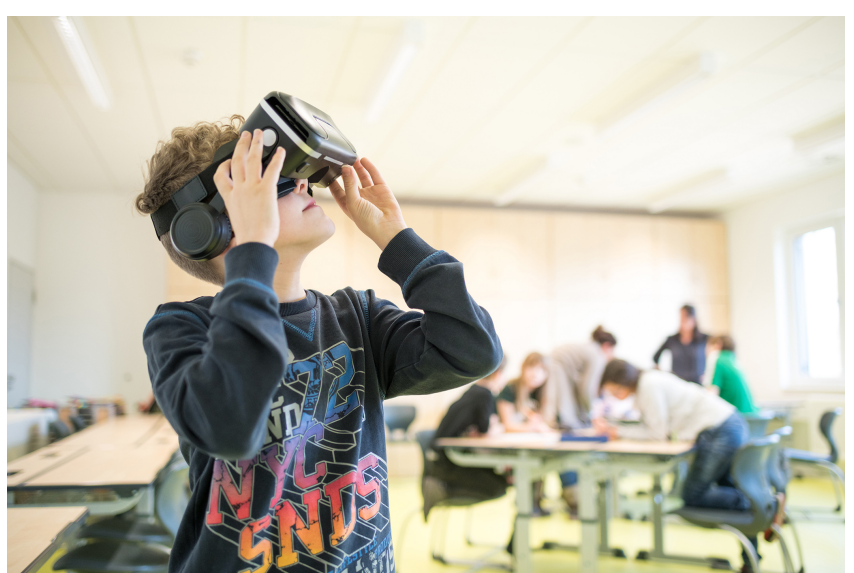

Figure 1. Pupil uses a VR cardboard with an inserted smartphone (photo by Chris Dormann).

\subsection{The feeling of presence}

This immersive technology immensely increases the possibility of users having an alternate reality experience (Slater and Sanchez-Vives, 2016:2). The reality addressed here refers to the experienced and perceived everyday reality of an individual human being. In VR, users can enter other worlds where they can move and act. It seems as if, in addition to the perceived reality of everyday life, a further, equally plausible reality is available to them. The experience is therefore different in VR than in the usual "view of a surface" (when the virtual world is presented on a screen). Slater (2009:3549) points out that VR is "a medium in which people respond with their whole bodies". They feel atmospheres and show attention and emotional involvement. As Slater and Sanchez-Vives (2016:2) describe it, "VR best operates in the space that is just below what might be called the 'reality horizon.' If a virtual knife stabs you, you are not going to be physically injured but nevertheless might feel stress, anxiety, and even pain." For example, at re:publica 2018 in Berlin, one of the authors of this paper experienced a $360^{\circ}$ video from WDR called "Berlin Terror" (WDR, 2017). The video shows how significant the spontaneous action of first responders is in disasters. The topic was the terrorist attack at the Breitscheidplatz in Berlin in December 2016. Scenes that symbolized the attack have a black background, and line drawings indicate what happened. The author did not manage to see the entire video rationally. In the middle, implied blankets floated down onto implied dead bodies. At that moment, the emotional involvement was so strong that the glasses had to be taken off. Even 2 years later, the memory of this scene still leads to emotional reactions. Even though it was perceived at a conference and as a line drawing, the diffuse feeling of having experienced the horrific situation oneself remains. Slater (2009:3549) describes this physical reaction as a feeling of presence. He attributes this feeling to a place illusion and a plausibility illusion. VR participants feel that they 
are in a different place, additionally to the physical place that they are at in that moment (feeling of being there). It is a bodily sense that is activated in this way (Dörner and Steinecke, 2019:55 f.). ${ }^{1}$ The virtual environment is perceived as objectlike (i.e. volumetric). The user's own volumetric perception is related to it. This creates a feeling of being plausibly surrounded by this world which leads to affective reactions. This perception works even if the virtual world corresponds hardly or not at all to human experiences. So, it is not a crucial factor that the virtual world looks as familiar as possible. The environment can consist of line drawings (as in the video from WDR) or geometric figures. The users' prior experiences and expectations reliably fill in missing information and create a credible space (Slater and Sanchez-Vives, 2016:4).

A second effect is "the illusion [about] what [is] apparently happening is really happening (even though you know for sure that it is not)" (Slater, 2009:3553). This plausibility illusion is strongly related to image and spatial perception. If people are immersed in virtual worlds, they experience "situations". These appear momentarily and holistically (Hasse, 2015:46; Kazig, 2007:177). In other words, users experience VR atmospherically. They feel the surrounding. This effect is well known from everyday experiences but also applies to images and VR (images discussed by Hasse, 2015:46). It is just as true for VR as it is for images that it demands all the senses. It goes beyond the purely visible and triggers imagination (Hasse, 2015:32 f.). In consequence, the VR situation seems credible on a more precognitive than cognitive level (Slater, 2009:3553; Slater and Sanchez-Vives, 2016:4). This simplifies the way of perceiving what is seen as authentic. According to Kerz (2017:357 f.), achieving authenticity depends on how perceivers participate in situations. They need a high intrinsic motivation. For this, their "antennae" must be addressed accordingly. The virtual world seems to make it quite easy to address these antennae. Kerz's research suggests that once authenticity is achieved, it lasts (Kerz, 2017:358). Additionally, VR includes a strong actionoriented component: people have to move in order to see the whole scene. They are even able to actively change the virtual world through their actions. This also has an influence on whether a situation is perceived as authentic. For instance, in the cliff scenario, in which VR users are supposed to jump off a virtual cliff or out of a skyscraper, some of them show signs of anxiety. Some are not able to jump even though they know they are physically in a safe space (Slater, 2009:3553 f.). The virtual environment fluctuates with the users' movements, and thus the users feel coupled to it.

\footnotetext{
${ }^{1}$ Experience in VR is multisensorial. It relates primarily to visual perception but also includes such body-related senses as depth sensibility (all sensations which relate to the position of the body) and kinetic perception (all sensations which relate to the movement of the body; see Dörner and Steinecke, 2019).
}

\subsection{VR in education}

The question is what difference VR makes. One part of the answer is that through VR, perception is integrated into standards and routines of digital communication. For psychology and the neurosciences, this is an opportunity to study behaviour and action under controlled circumstances (Slater and Sanchez-Vives, 2016:6 f.). Researchers in these fields discuss therapeutic influences of VR. A study by Seinfeld et al. (2018), for example, placed men who were violent towards women in female avatars and exposed them to situations of verbal and physical violence by men. The study showed a significant increase in the empathic ability of the men after the experiment. Another study placed people with racist attitudes in avatars with a different skin colour. In this case a reduction in racist attitudes could still be demonstrated after a longer period of time after the experiment (Banakou et al., 2016). If people think that events in VR are happening (plausibility illusion), they even show authentic behaviour in VR (Slater, 2009:3553). Sanchez-Vives and Slater (2005:334) refer to several behavioural or physiological reactions to presence in VR, such as swaying or an increasing heart rate. However Bailenson (2018) explains in this context the following: "There is no medium that magically produces empathy." But in "VR, content that moves the body will also move the mind." Equally, such studies demonstrate the potential power and danger of this medium. Due to their proximity to human perception, media such as VR create a simulated world that is difficult to question (like such media of perception in general; see Spangeberg, 1996:268). First, users immerse themselves in the scene. It is not until later that they realize the artificiality of the situation. This has farreaching consequences. As Schöne et al. (2019) showed, actions in VR can be processed like real memories: participants experiencing a motorcycle ride in a $360^{\circ} \mathrm{VR}$ environment performed significantly better in memory tasks than participants watching a $2 \mathrm{D}$ video of the ride. The authors argue that immersive experiences can be included in an extensive autobiographical memory network.

Basically, there is a growing interest in using VR in wider educational areas, e.g. to illustrate problems or to foster the ability to cope with unknown situations (Bailenson et al., 2008:108). There are already various educational offers commercial or non-commercial - that work with VR technology, even for schools (e.g. Google expeditions). Therefore, it is necessary to reflect on the use of VR in educational contexts, with reference to specific educational requirements. Especially as events in VR are perceived (and remembered) as real, it must be ensured that VR experiences are neither overwhelming nor manipulative. ${ }^{2}$ At the same

\footnotetext{
${ }^{2}$ This also includes the use of this technology. A study by Southgate et al. (2019) on ethical implications of VR use in classrooms found that especially girls feel uncomfortable wearing a headmounted display in class, as they could no longer perceive what was happening around them. This calls for a critical consideration
} 
time, this means that digitality has to be dealt with conceptually. As Stalder (2018:15) points out, whoever controls the infrastructure by determining the parameters controls what can happen. Universities should have an influence on which content-related and didactic priorities are set in the use of digital media in general and VR in particular.

\section{Acquirement and mediation}

In summary of the previous section, VR can be conceptualized as an augmented image: a designed virtual world in which things are seen, emotions felt, atmospheres perceived, and situations experienced. In the following, we will focus on VR in the context of geographical education. As we will discuss in more detail in Sect. 4, students developed VR field trips (VREXs) based on their own research results on current urban development processes. ${ }^{3}$ The VR field trips are designed as $360^{\circ}$ walk-throughs. For this, $360^{\circ}$ recordings were made at various locations in the city. The challenge in this context was suitable places in the cities of Vienna and Berlin that "work" in VR. For this, the students had to combine felt urban atmospheres and observed urban practices - related to their research fields. In order to construct VR field trips a particular practice of sense-based acquirement and a particular (visual) practice of mediation is needed (Schlottmann and Miggelbrink, 2015a).

\subsection{Sense-based and content-based acquirement}

VR refers to the reality of a perceived world and works on "our physical sense of being in spaces" (Machin, 2014:8). According to Dodge et al. (2008:4), spatial perception is the most powerful information-processing ability of humans. VR is a surrounding space that can be perceived atmospherically, and it creates spatial knowledge in a powerful way. Surely the experience is highly influenced by the design of the VR. But according to atmospheric research, every situation (physical or virtual) could only hold the potential for atmospheric feelings (Kazig, 2007:179). It is a challenge to identify the un-

of safe spaces in VR learning environments in such a way that they are discussed in the context of vulnerable groups (e.g. Bustamante Duarte et al., 2021).

${ }^{3}$ The project is based on the notion of students creating VR instead of using it. We ground this approach on two aspects: on the one hand, we assume positive effects on geographic capabilities and subject-specific digital media literacy by students actively creating VR (Hellriegel and Čubela, 2018; Schulze et al., 2020). Empowering learners to reflect on VR and its effects on spatial learning is crucial, as VR is both an increasingly used and a powerful communication medium. On the other hand, we argue that state-of-the-art geography teaching needs to include modern learning technologies, such as VR learning environments which reflect the current state of research. We postulate a responsibility for geography researchers (including learners) to create appropriate VR learning environments and concepts to implement VR in geography education. derlying mechanism. Kerz (2017:358 ff.) identifies different phases of immersion in places that enable both atmospheric perception and authentic experience. Various factors such as a good balance between familiarity and strangeness as well as personal expectations of the place and intrinsic motivations can have an influence here. Kazig (2007:179 ff.) asks in general what materiality situations require or what the quality of the environment should be. Research on shopping atmospheres, for example, suggests that some conditions seem to influence the quality of atmospheric experience. However, no effect structure can be observed here; only probabilities can be formulated. This could be transferable to VR worlds. ${ }^{4}$ But one aspect should be treated differently: VR is a digitally designed world with an underlying concept of content. Thus, experience and atmosphere depend highly on the purpose of the VR. That is why the researcher and the designer of VR must pay attention to atmospheres (in our project, every student assumes both roles). Researchers generate atmospheresensitive content; designers integrate that into the production phase. This requires that both parties have the opportunity to experience urban space atmospherically and also understand how this changes research processes.

Second, the practice of acquirement refers to the content. VR shows specific scenes. For example, the user stands on the side of an urban crossroads, on a narrow pavement, with cars awfully close. Everyone may have a quick association with this - for instance, the feeling of insecurity. But the situation is first a non-specific trace. It only suggests urban processes and structures without making a clear statement. The choice of locations for a VR field trip depends largely on the prior knowledge and interest of the researcher and the designer (for this process the role change from research to production is significant, as we will show later). This is determined by the subject matter - in our case urban society-environment research fields. Here, it can be assumed that the researchers have already incorporated social spatial processes into cities (Hubbard, 2018:216). They have expectations inscribed in the body about how to experience situations and space (Strüver, 2020). It is an everyday practice of urban life that people are part of cities through their bodies. This may also influence the way traces are interpreted in the city as well as in VR.

\subsection{Mediation of space and content}

Therefore, from a geographical learning perspective, VR requires a specific mediation practice. The goal is to understand and reflect on practices of sense-based and content-related acquirement. To do this, we have focused on the entire process of producing VR: from research on the subject to the

\footnotetext{
${ }^{4}$ However, more research is needed to fully grasp this atmospheric relating of the body to VR environments and to be able to describe it as a practice of sense-based acquirement especially for geographic learning.
} 


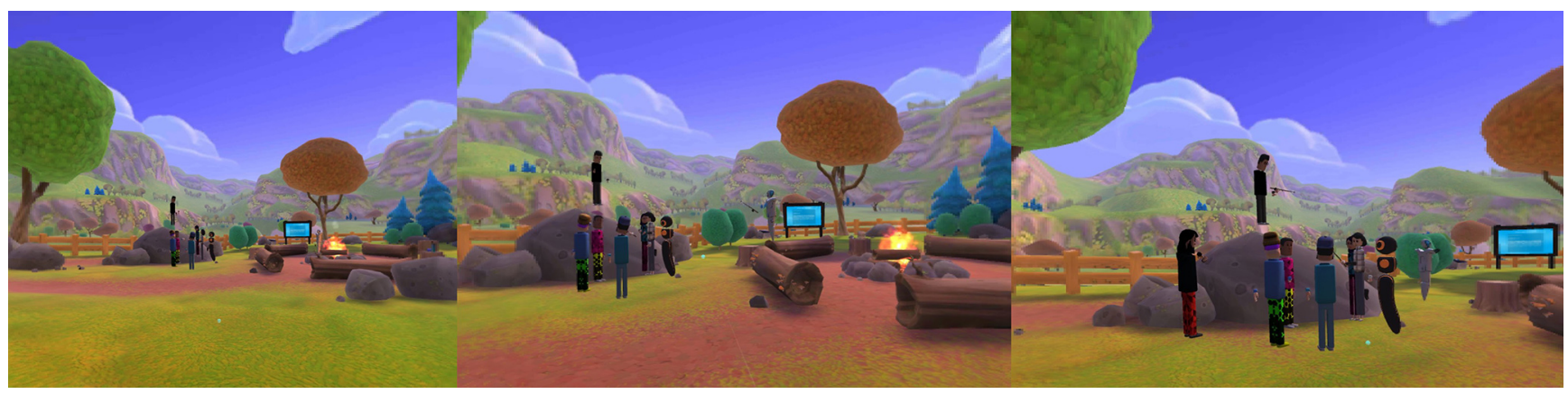

Figure 2. Moving through a scene in AltspaceVR (photos by Lena Florian).

design of VR field trips. During this we aim to enhance critical reflections on spatial knowledge and geographical content knowledge. We questioned the function of VR and linked it to the process of constructing space and content.

The key factor for mediation is that VR is a form of geographic visualization. Dodge et al. (2008:4) point out that geographic visualization "exploits the mind's ability to more readily see complex relationships in images $[\ldots]$ by helping people to see the unseen, premised on the simple notion that humans can reason and learn more effectively in a visual environment than when using textual or numerical description." But they also point to the opposite side. Geographical visualizations inform, but they can equally deceive. The type of programming and the interests of the designer are powerful. Ethical or normative problems may arise, or problematic political interests may be embedded (Dodge et al., 2008:6 f.; Schurr and Strüver, 2016). Dodge et al. (2008:7) summarize as follows: "It must be recognized that geographic visualization is a process of creating, rather than revealing, spatial knowledge. Throughout [this process] a large number of subjective, often unconscious, decisions are made about what to include and, possibly more importantly, what to exclude". VR - especially as a $360^{\circ}$ version - is a form of geographical visualization that seems to be very vulnerable here. The virtual reality shown seems unambiguous. It corresponds closely to everyday and incorporated expectations. An initial "naïve image reference" is highly likely (Hasse, 2015:36). Therefore, the VR design must be considered in its powerful effect. For this purpose, a critical reflexive visual competence should be achieved (Nöthen and Schlottmann, 2015:34), and in addition, in VR the bodily perspective is an important part of this. One way of doing this is to analyse images (e.g. VR as augmented images) for their implicit or explicit content (Schlottmann and Miggelbrink, 2015a:17). Images are visual artefacts both in their holism and in what is presented. Thus, they symbolize and include traces which indicate geographically relevant content. Mediation should enable the deconstruction of traces as artefacts for socially produced meaning (Hard, 1989:5).

Therefore, Hard (1995:62 ff.) outlines a helpful research methodology that addresses empirical research in general.
He refers to three critically reflexive processes which he calls "fantasies" (a nice way to refer to the creative aspect of critical reflection). They are

- first, understanding traces as the result of hypothetical ideas and "confirming, supplementing, correcting, or overturning" them through further traces ("trace fantasy");

- second, not being satisfied with the first interpretation but questioning the underlying hypotheses by competing hypotheses ("hypothesis fantasy");

- third, testing the hypotheses further through triangulation, i.e. using further empirical methods to understand presumed social processes ("operationalization fantasy").

We understand these three processes as the basic methodology of interpreting artefacts - whether in the field, in the image, or in VR. Therefore, they are relevant to the production of VR and the associated research process as well as to VR acquirement. An important consequence of the aspects discussed before is that the body-related part must be integrated into all three phases. According to Schurr and Strüver (2016:94), this means the adoption of a "more than representational perspective", i.e. bringing out the emotional and affective dimensions of traces, hypotheses, and operationalization. An equally important consequence is to make visual mediation part of the fantasies. Therefore, we add a fourth fantasy: the digital visualization fantasy or the principle of digital tracing. This fantasy relates to the process of designing VR as an augmented image. Here, we aim to question visual decisions, e.g. the choice of places and situations for $360^{\circ}$ images. The designer should change perspectives both the perspective of one place to another and the perspective of designer (producer) to user (consumer).

\section{VR field trips (VREXs)}

An underlying question is which VR worlds are suitable for geographic academic teaching programs. In general, they appear to be useful for triggering processes of understanding 


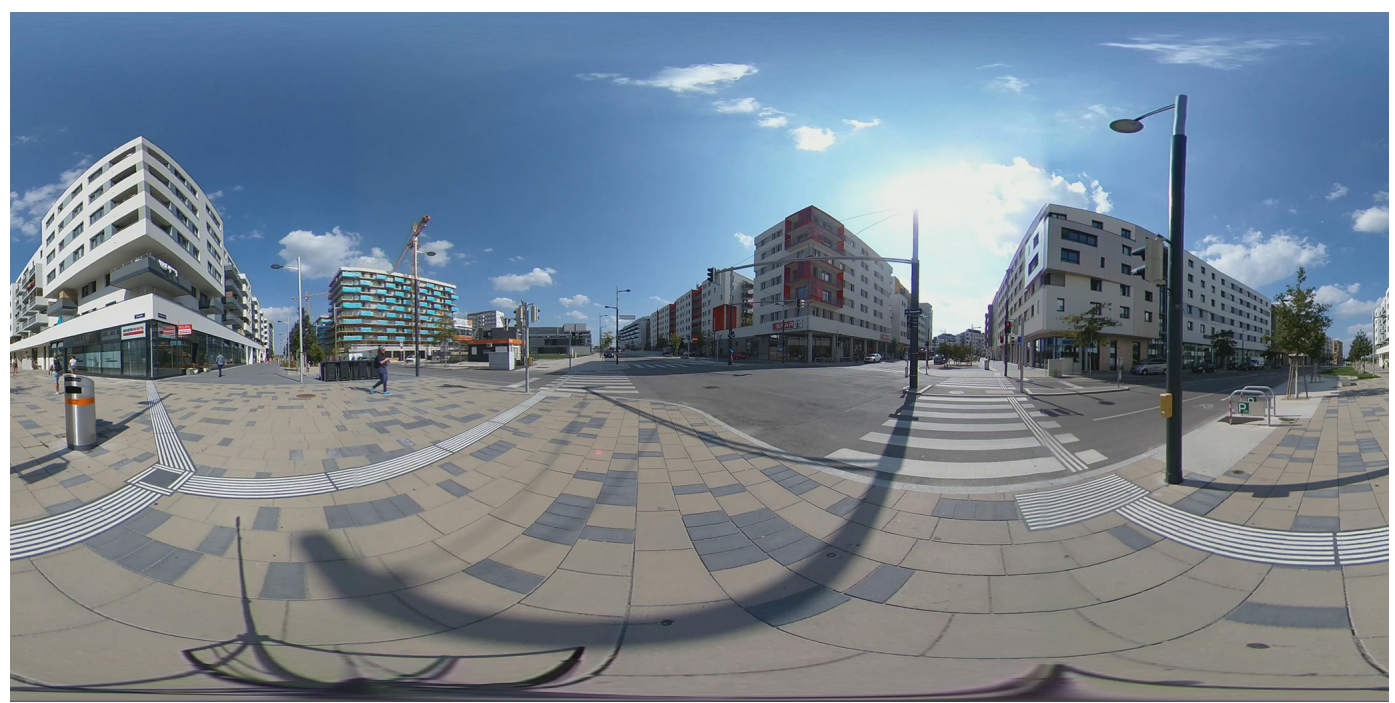

Figure 3. A $360^{\circ}$ panoramic image of Seestadt Aspern, Vienna (own photo).

in which the body takes part, whether it is a matter of attention, empathy, changing perspectives, or understanding complex relationships through spatial imagination. In our research and teaching programme, we work on VR projects with reference to urban spaces. Our focus is on different views of urban society-environment relations. There is a variety of research here. We selected four current debates: "green city", "sustainable city", "smart city", and "resilient city" (Rink and Haase, 2018). The bodily, emotional, and atmospheric perspective could supplement these debates. In general, subjects with their bodies could be understood as urban artefacts: they move, "rest", and "encounter" (Hubbard, 2018:213) and thereby show their relation to the city. They appropriate urban space but also point to disturbances or to inequalities in social power relations and urban planning (Hubbard, 2018:209 ff.; Strüver, 2020:287). These are effects that occur as everyday or professional attributions on bodies or as part of social decision-making processes. But phenomenologically, our priority is to understand the holistic atmospheric perception of subjects. We want to work out the relationships that result from this (Böhme, 2016:101) and to "sharpen attention" to oneself and the object (e.g. the urban nature, Hasse, 2017:48). ${ }^{5}$ In the following, we elaborate how we methodologically linked research and design processes and the requirements presented in Sect. 3. Hereby, we want to show and discuss, by drawing on three examples, how atmospheric experiences were "brought up" in relation to urban practice (understanding traces) and visual practice in constructing VR (laying traces).

\footnotetext{
${ }^{5}$ We evaluated the course concept with the help of participant observations and individual and group interviews.
}

\subsection{Concept}

In the summer terms of 2018 and 2019, we developed a course concept as a joint project of geography education and human geography at the University of Potsdam. The teaching partly took place in Vienna and Berlin (for Vienna see Mohring and Brendel, 2020). ${ }^{6}$ The students worked in research groups. Each group created its own research design, conducted research in Vienna or Berlin, and developed a VR field trip. The aim was to critically reflect on urban processes in relation to the own-body concepts and link them to the process of producing VR. Therefore, the VR field trip took up the idea of constructivist tracing in field trips with regard to visual and body-related aspects (Nöthen and Schlottmann, 2015; Dickel and Scharvogel, 2013). This connects to both the trace-related research design during the course and the VR field trip concepts the students develop. Moving through field trips and VR field trips should be characterized above all by free discovery. As far as possible, the students should be encouraged to move around and make free decisions for and against viewing and changing locations. ${ }^{7}$

\footnotetext{
${ }^{6}$ The course practices differ here. In Vienna, we conducted a $6 \mathrm{~d}$ field trip (with a preparation block and a follow-up block; Mohring and Brendel, 2020). In Berlin, it was an ongoing course, and we integrated two single-day field trips in Berlin. In terms of emotional attachment and intensity to the research topic, Vienna was a greater success.

${ }^{7}$ Technically, the VR field trips are based on $360^{\circ}$ images and videos. They were taken in urban space. Some of the video sequences were underlaid with the original sounds of the locations. To enable a walk-through, the recordings are virtually linked via stitching points. For this, the students developed storyboards. For more detailed access to the research content, visual 2D information (images, texts) and audio files are added. Users can watch the VR field trips with smartphones and a phone-based cardboard headset.
} 
Methodologically, we arranged the course design into the four phases described in Sect. 3.2. Practically, we separated it between a preparatory meeting, a phase on site (in the city), and a follow-up session. For the preparation, the students chose a research topic and worked up related sources (text work). We discussed their own underlying concepts of urban development in general and of Vienna or Berlin by reflecting on visual impulses (video reception and own images). These tools both prepare and are part of the trace, hypothesis, and visualization fantasies. On site we first worked on urban conditions of field trips, reflecting exercises, interviews with experts, and lectures. We experienced this as a whole group, but each student was always encouraged to reflect on their own concepts about traces (focusing on the research topic, trace fantasy). Based on this the students developed hypotheses about the underlying social mechanism of the traces they experienced. In Vienna, the group focusing on green cities, for example, resonated with a small urban garden in the middle of canyons and streets. In this place every corner was greened; even the wall of the house was planted with moss. It was a small and yet very contrasting place in the metropolitan milieu. They connected to the research focus that interprets urban gardens as a form of nature appropriation and community experience (hypothesis fantasy). The research was inspired by their own feelings of experiencing nature as valuable in the city. They found the small place with its greenery and the many signs of community (small messages, benches and seating, the chaos of many shaping hands) congenial. It radiated a sense of well-being. Based on this, they expanded their understanding of traces by researching further urban gardening projects and conducting interviews with the gardeners (operationalization fantasy). Based on this, they planned their VR field trips. The course ended with a follow-up session in which we reflected on our findings.

Our concept included a specific learning arrangement. We learned that all research phases, on the one hand, take place during the whole course time but, on the other, need impulses at certain times. Especially in Vienna, we organized reflection and discussion periods at different locations. We carefully selected the places for them: open places like a meadow for free associations; an island situation, alone on a covered terrace of a café in pouring rain, for a fundamental discussion on sustainability (here, the group needed a feeling of closeness); and a co-working place in a library for the final reflection and evaluation. We did not plan all the locations in advance. This design was possible because we, as the lecturers, were attentive to the specific atmosphere. To empower the research fantasies, we used typical reflection methods to question traces, hypotheses, and operationalization plans (reflection diaries, peer feedback, group discussions, etc.). But for this, we created a mindset through specific questions or exercises to help express the feeling of atmospheres - as the following three examples show.

\subsection{Video reception}

At the beginning, we watched two YouTube videos. One shows Solarpunk ${ }^{8}$ visions: images of a green and high-tech future society, underlaid with music (Sieudiver, 2016). The other shows an apocalyptic and critical vision of an ecologically destroyed society (Greenpeace Deutschland, 2009). Afterwards, we asked the students to describe their impressions. During the discussion, content-related questions were gathered which were mainly related to society and the future. They assessed the urban present rather negatively in terms of the relationship between society and the environment. All in all, a more pragmatic or even pessimistic view of the future prevailed. It is noticeable that the students resonated with visual impressions. Here, Solarpunk offers futuristic images which were highly discussed: the students emphasized the greenery and the impression of closeness to nature but also the impression of perfection and uniformity. Some looked for related images or scenes, e.g. cities like Singapore or video games. Often the description was combined with a rating, which was rather critically distanced. They questioned the vision itself ("absurd", "exaggerated", "too much future"), the presumed idea ("not sustainable", "growth idea", "practicability?"), or the visual offer ("constructed, from one hand", "too green"). During the discussion, some underlying assumptions of the students emerged. First, they questioned the relation between greenness, on the one hand, and sustainability, on the other. Second, they criticized the visual mode in the meaning of "beauty is not an end in itself". During the group discussion the students rarely showed conspicuous emotions. Some emerged, nevertheless. One student expressed a shudder at first because she suspected that the monumental skyscrapers were not only aesthetically pleasing and beautiful at the top but also unattractive and dark at the bottom. She feared a hidden, invisible dimension. Less clear, although also noticeable, was the rejection of the positivity in general. This is more interesting as the second video of Greenpeace which shows a dystopia of a destroyed and grey landscape was rather accepted (as a frightening "horror scenario").

\subsection{Reflexive exercise}

During our on-site field trips to Berlin and Vienna, the students were supposed to reflect on their feelings and perceptions of urban places. For this purpose, we conducted a reflexive exercise. Based on our feelings towards the chosen places and our perception of them being worthwhile, we chose the places for this exercise spontaneously. In both towns we explored the places in advance. In Vienna we stood on a large meadow in the middle of a newly built district, the Seestadt Aspern. In Berlin, we were in a café with lots

\footnotetext{
${ }^{8}$ Solarpunk activists design a future for human society literarily, visually, and creatively. Their ideal consists of an "ecological holism" (Schuller, 2019:9) in a highly technological society.
} 
of wood and bamboo hedges between office buildings on the EUREF campus. Both places are developed according to smart and sustainable goals. In Aspern, the focus was on housing and traffic concepts but also on the design of open spaces and the facilitation of coexistence. At the EUREF campus business, research and new technologies dominated, and places for co-working were created. The students took up a pose to express how they perceive the atmosphere of the places. Part of the exercise was to talk about the poses. In Seestadt Aspern, the attitudes were expressive. One part of the group showed a clearly negative attitude. The student on the left in Fig. 4 rejected the place completely and shook herself at the idea of having to live in this place. The student on the right explained that he wanted to adopt the most unnatural body position possible. To him, Aspern was unnatural and uniform. The students also named "emptiness", "no community", "anonymity", and "isolation". But there were also students who perceived neighbourhood, looseness, and relaxation. Their attitudes were mostly related to the idea that it could be their own place of living. Only one student remained on an abstract level and reflected on the planning and practicability of the district in general. On the EUREF campus, on the other hand, the students were rather helpless in finding a good pose. Many poses expressed thoughtfulness or deliberately left no statement (normal sitting posture or crossed arms, like the students in the middle in Fig. 5). These poses do not represent a refusal of the task but a distance from the place. The descriptions of the atmosphere were less emotional than conceptual. The student on the left in Fig. 5 wanted to express that the planners want to be "high up" in that place. The student on the right symbolically showed a pair of binoculars to make clear that she must look even further to discover the dimensions of the place. Because of the vagueness of and uncertainty in the atmospheric descriptions in this place, the exercise was repeated in another seminar. This consolidated the view that most of all students do not resonate with this place. The students saw "no place" for themselves here. Only one group chose this location for their VR field trip.

\subsection{Change in perspectives}

The third example does not refer to a specific exercise but describes a process. During their own research process, the students had already dealt with the question of how to translate the research results into a VR field trip. Quite early they started to weigh up which places were suitable. A challenge for us, therefore, was to ensure the quality of research as a result of the fantasies of trace, hypothesis, and operationalization. Especially in Vienna, we realized that the change from research to design must be actively organized. The students had to engage in the process of mediation. This process was associated with uncertainty. The challenge lies primarily in the critical constructivist attitude to the process of laying traces, i.e. the design of a VR field trip. Our evaluation

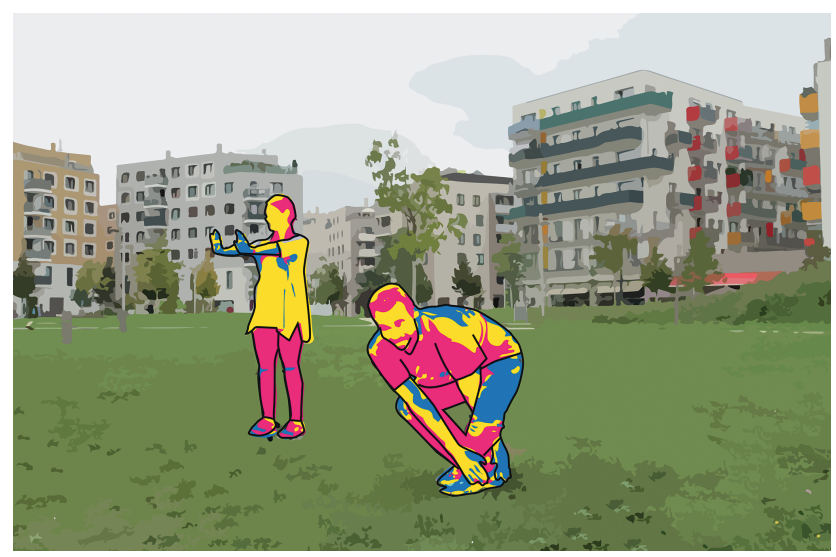

Figure 4. Posing exercise in Seestadt Aspern, Vienna (own photo, illustration by Ute Dolezal).

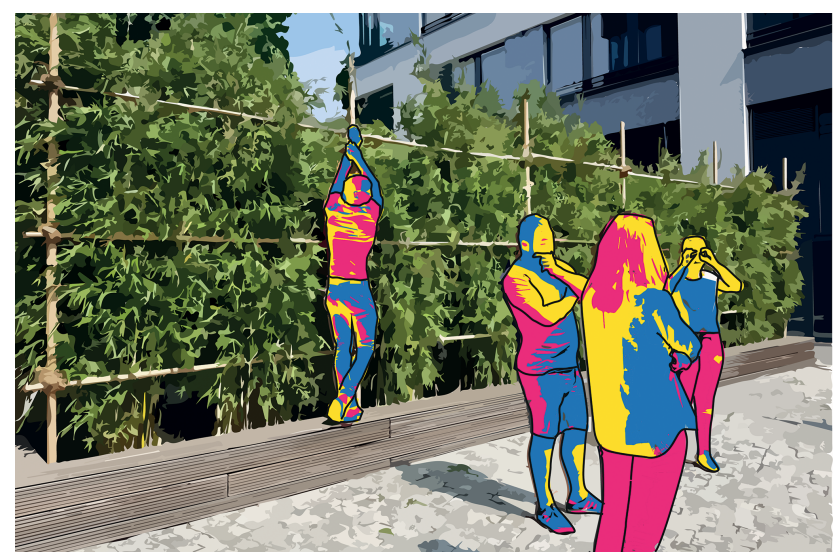

Figure 5. Posing exercise at the EUREF campus in Berlin (own photo, illustration by Ute Dolezal).

suggests, on the one hand, that the students understood the design of VR field trips as subjectively "constructing" a version of reality. On the other hand, only a few students were aware that viewers of VR learning environments do not necessarily have to follow the perceptions of the designers laid out in VR (i.e. only perceive what was "put in" during the design process; Brendel and Mohring, 2020). With the help of peer-to-peer feedback and group discussions, the students rearranged their research findings to find a mediation focus of their VR field trips. In order to be able to select the specific locations of the VR recordings, they must assume perspectives of possible users. It was important to connect this with possible visual perspectives in VR. For example, is it important to integrate narrowness or expanse, smallness or size, and proximity or distance? Are entrance situations, borders, or contrasts important? Based on their experiences of atmospheric perception, the students decided in favour of locations and perspectives and photo or video and in favour of or against sounds. Figure 3 in Vienna, Seestadt Aspern, for example, shows a pavement with plenty of space for pedes- 


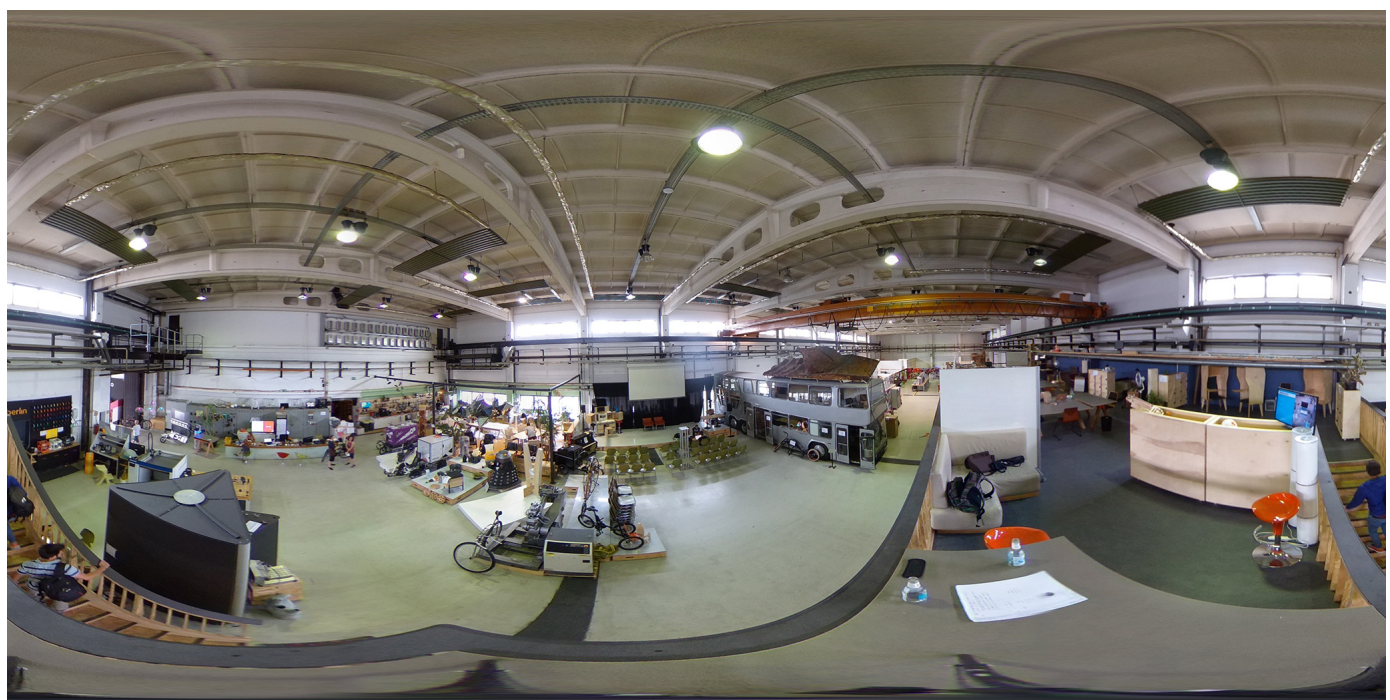

Figure 6. A $360^{\circ}$ panorama of the MotionLab entrance in Berlin (own photo).

trians. The image contrasted with a scene in Vienna's city centre, where pedestrians hardly have any space. The student's aim was to draw attention to the individual well-being of people in traffic.

Some groups struggled to visually translate their insights from urban practice. This concerned, for example, the groups dealing with sustainability. The groups worked with the hypothesis that the social dimension should be highlighted. Their main interests were social justice and bottom-upprocesses, according to Brocchi (2017). Figure 6 shows the example of a social sustainability research group in Berlin. They opted for an urban location within a building. No public place during our field trip in Berlin seemed suitable for them. Their aim was to show MotionLab ${ }^{9}$ - an example of a makerspace - in its various facets. They were concerned to show the opportunities of and the uncertainty in bottom-up movements and common work. For this they chose a multiperspective representation. The scene shown in Fig. 6 is intended to show the "social pivot" of MotionLab. A student explains, "We want to show the image of what you get from MotionLab when you enter it. You have a direct opportunity to see what co-working can mean on a cooperative or social level." To understand the social situation, certain actions such as conversations and activities were staged on the photo. This was contrasted not by other images but by audio files with interview statements. These audio files are integrated into the VR field trip. They highlight the invisible, hidden complexity of this place.

\footnotetext{
${ }^{9}$ MotionLab is a makerspace that provides users such as startups or hobbyists with a selection of expensive hardware and software that can be used collectively. The entire infrastructure is designed to enable community living (kitchen and common dining area, fitness equipment, events, etc.).
}

In summary, we have given the students space and time to describe situations they have experienced and to express their sensual feeling. The aim was to stimulate reflection on one's own viewing and feeling of spatially related aspects and to link this with content-related expectations of urban research. We applied this strategy both to images, as in the first example, and to urban situations, as in the second. Sensitivity to their own body concept helped the students to manage the role change from researcher to designer, as described in the third example. For example, two teams included Seestadt Aspern in their research. It was obviously not a question of whether a place was perceived as positive but whether it aroused any subject-related resonance at all. During the courses, the students were empowered to develop a spatial reflection and a visual reflection competence. Especially, they understand VR as a geographic visualization process which is in a way powerful, uncertain, and selected. Likewise, they integrate their own spatial perceptions and their own body concepts in their research practices. In part, also the limits of one's own knowledge were understood. For example, one student emphasized that he could not make any statement about the whole city of Vienna. However, there was an increasing sensitivity to local particularities and the exemplariness of the selected places. Furthermore, during the production and design process, the students worked on a feeling for perspectives and possibilities and limits of the expressiveness of the image and equally on the necessity of image changes (such as a change of location in VR) and the conscious elaboration of the specifics of the locations. The own-body concept played an important role in this. However, the "visualization fantasy" created a new resonance between body and place. And it underlined the limitations of visual impressions in the context of specific research foci. Every group added additional text or audio files to clarify their subject. Our evalu- 
ation also showed that, on the one hand, the students very much appreciated the possibilities of a field trip designed in a constructivist way. On the other hand, they found it difficult to transfer this approach into a VR field trip. In the design phase, the desire to control the users' trace interpretation prevailed. Perhaps this is a problem of experience: students are still more in the role of consumers by using digital media as part of learning. What is needed here is a stronger understanding of the possibilities of actively appropriating VR to feel empowered to decide in favour of and against viewing, changing perspectives and locations, and so on, even during its use.

\section{To conclude - the way to mindfulness}

VR is in some ways a disruptive technology. It integrates perception into routines of digital communication. Like an augmented image, VR can be perceived atmospherically. Therefore, VR is a powerful geographic visualization that creates felt virtual spaces. That is why we see the need to understand VR as a visual mediation practice which is linked to sensebased and content-related practices of acquirement. It is necessary to research the structural relationship between atmospheric perception and virtual environments. Consequently, we tested a concept that approaches the use of VR in education in a mindful way. We focused on the process of producing. Here, we integrated the phenomenological view. This view enables access to body and emotion. In VR, particularly the neurosciences measure strong affective responses at a precognitive level. Atmosphere-sensitive spatial research, on the other hand, takes this phenomenon as a holistic perception process, subject-related and situated. In terms of geographical education, it needs to be deconstructed and reconstructed how VR is linked to sense and body. People acquire their environments - whether physically or virtually. Many expectations are stored as body knowledge and are not necessarily always conscious. Nevertheless, this has an influence on how processes are interpreted. Therefore, holistic experiences should be separated and questioned.

However, we want to end with reference to the aspect of mindfulness in general. First, we return to the subject of urban research. We chose this subject as relevant for VR environments - especially with the focus on atmosphere and body. This dimension points far beyond the pure understanding of urban processes (Hasse, 2017). According to Hubbard (2018), it is a question of how urban geography can generally orient itself in the 21 st century. He argues that discussions about futures of cities in terms of society and environmental relations could "reinvigorate urban geography" (Hubbard, 2018:5). In addition to research on social meaning, "we need to explore [... ] practical and embodied skills which are woven, almost subconsciously, into the lives of urban citizens" (Hubbard, 2018:225). Mindfulness in this context means the inclusion of the affective and emotional level in geographical urban research. Second, more generally speaking, VR makes it abundantly clear that the affective and bodily part of communication must be considered. For us, this is a decisive impulse to think about the way in which dissemination media change our communication. It is about how standardized routines make certain forms more likely. As we have shown, this is not about the difference between digital and non-digital. It is about the way in which the body is accessed (this also applies to audio signals, for example). Digital media are just immensely more flexible and successful in distribution. To understand this, we need a general awareness of our own body concepts. This needs a transformation of education because now aspects of mental attitude (e.g. Sanders, 2017), well-being (e.g. Seaford, 2018), resonance (e.g. Rosa, 2016; Beljan, 2018), and mindfulness (e.g. Manemann, 2014) are becoming important. Third, these aspects are generally seen as possible ways to deal with a disturbed society-environment relationship. Hasse (2017:55 f.), for example, points out that a main problem is the disturbance of the human-nature metabolism. According to Hartmut Rosa, this is a crisis of modernity: a crisis of the relationship between people, on the one hand, and other people, nature, and things, on the other (Sanders, 2017). It is the problem of a missing sense for the well-being of all life. Or, as Manemann (2014) describes it, it is a crisis of the growing incalculability of the world with a simultaneous desire to control nature. This results in a new paradigm of resilience, i.e. the strengthening and creation of resistance to dealing with change (Manemann, 2014:60). Hasse (2017) points out that the human being must be addressed in their concern for themself. We need a new perspective, an understanding of an "us-world" (Egner, 2017:18). For this, phenomenological programs are necessary that enable the feeling of oneself and thus make the culturally hidden basis of all action visible. Manemann associates this with the hope that a care for the self will become a care for the community. He refers to this as mindfulness and means above all a transformation of the self to face transformations in society and emphasizes the major role of education. Learners should be empowered to become self-effective and mindful and to gain new insights (Manemann, 2014:78 ff.). Therefore, incorporating this dimension into geographic academic and school teaching about urban processes is a way to strengthen caring for one's self and others. We discussed our concept and three different examples of our project to suggest what such teaching could look like. In doing so, we did not adopt a dualism of nature and digitality, but we made clear how hybrid perspectives can be adopted starting from a basic constructivist concept. Our overall aim was to educate mindfully, especially promoting multi-perspective thinking without overpowering, strengthening reflected and enlightened thinking in dealing with transformation, and stimulating mindfulness and the ability to act. That means understanding and considering one's own and other peoples' needs, acknowledging 
challenges, and reaching options for action and decisions together.

Data availability. This research is based on qualitative data and a small set of participants. In order to comply with privacy policies, the data cannot be shared.

Author contributions. Both authors conducted the research in equal share but with different disciplinary foci (KM focuses on human geography, NB on geography education). The manuscript for this article was written by KM and commented on and edited by NB.

Competing interests. The authors declare that they have no conflict of interest.

Disclaimer. Publisher's note: Copernicus Publications remains neutral with regard to jurisdictional claims in published maps and institutional affiliations.

Acknowledgements. We would like to thank the students who developed the VR field trips very much for their commitment and valuable feedback. We would also like to thank the two anonymous reviewers for their highly constructive and helpful comments.

Review statement. This paper was edited by Antje Schlottmann and reviewed by two anonymous referees.

\section{References}

Baecker, D.: Form und Formen der Kommunikation, suhrkamp taschenbuch wissenschaft, Frankfurt am Main, 2005.

Bailenson, J.: How to create empathy in VR: available at: https://www.wired.co.uk/article/ empathy-virtual-reality-jeremy-bailenson-stanford (last access: 19 February 2021), 2018.

Bailenson, J. N., Yee, N., Blascovich, J., Beall, A. C., Lundblad, N., and Jin, M.: The Use of Immersive Virtual Reality in the Learning Sciences: Digital Transformations of Teachers, Students, and Social Context, J. Learn. Sci., 17, 102-141, https://doi.org/10.1080/10508400701793141, 2008.

Banakou, D., Hanumanthu, P. D., and Slater, M.: Virtual Embodiment of White People in a Black Virtual Body Leads to a Sustained Reduction in Their Implicit Racial Bias, Front. Hum. Neurosci., 10, 601, https://doi.org/10.3389/fnhum.2016.00601, 2016.

Beljan, J.: Resonante Weltbeziehungen, in: Kritische Lebenskunst, edited by: Gödde, G. and Zirfas, J., J.B. Metzler, Stuttgart, 433439, 2018.

Böhme, G.: Naturphänomenologie, in: Handbuch Umweltethik, edited by: Ott, K., Dierks, J., and Voget-Kleschin, L., J.B. Metzler, Stuttgart, 100-105, 2016.
Brendel, N. and Mohring, K.: Virtual-Reality-Exkursionen im Geographiestudium - neue Blicke auf Virtualität und Raum, in: Augmentierte und virtuelle Wirklichkeiten, edited by: Beinsteiner, A., Blasch, L., Hug, T., Missomelius, P., and Rizzoli, M., Medien Wissen Bildung, Innsbruck University Press, Innsbruck, 189, 2020.

Brocchi, D.: Transition Neighbourhoods, in: Die Experimentalstadt, edited by: Reinermann, J.-L. and Behr, F., Springer Fachmedien Wiesbaden, Wiesbaden, 131-161, 2017.

Bustamante Duarte, A. M., Ataei, M., Degbelo, A., Brendel, N., and Kray, C.: Safe spaces in participatory design with young forced migrants, CoDesign, 17, 188-210, https://doi.org/10.1080/15710882.2019.1654523, 2021.

Chen, S. E.: Quicktime VR: An image-based approach to virtual environment navigation, Proceedings of the 22nd annual conference on Computer graphics and interactive techniques, $\mathrm{Au}-$ gust 1995, Los Angeles, 29-38, 1995.

Dickel, M. and Scharvogel, M.: Geographische Exkursionspraxis: Erleben als Erkenntnisquelle, in: Geographiedidaktik. Ein Arbeitsbuch zur Gestaltung des Geographieunterrichts, Studienbücher der Geographie, Bornträger, Stuttgart, 176-185, 2013.

Dodge, M., McDerby, M., and Turner, M.: The Power of Geographical Visualizations, in: Geographic visualization: Concepts, tools and applications, edited by: Dodge, M., McDerby, M., and Turner, M., John Wiley \& Sons Ltd, Hoboken, 1-10, 2008.

Dörner, R. and Steinecke, F.: Wahrnehmungsaspekte von VR, in: Virtual und Augmented Reality (VR/AR), edited by: Dörner, R., Broll, W., Grimm, P., and Jung, B., Springer, Berlin, Heidelberg, 43-78, 2019.

Egner, H.: Was bedeutet das Anthropozän für uns als Gesellschaft?, in: Tagungsband zur Tagung, Anthropozän - ein neuer Blick auf die Erde als unseren Lebensraum, 25-26 September 2017, Nationalparkverwaltung Kärnten, Kärnten, Austria, 17-21, 2017.

Greenpeace Deutschland: Der Energieriese von RWE: available at: https://www.youtube.com/watch?v=xZFGYG7acz4 (last access: 10 August 2021), 2009.

Hard, G.: Geographie als Spurenlesen, Z. Wirtsch., 33, 2-11, 1989.

Hard, G.: "Spuren und Spurenleser" Zur Theorie und Ästhetik des Spurenlesens in der Vegetation und anderswo, Osnabrücker Studien zur Geographie, 16, Rasch, Osnabrück, 1995.

Hasse, J.: 2. Das Bild - ein visuelles Medium?: Phänomenologische Bemerkungen zu einem sensualistisch-reduktionistischen BildBegriff, in: Visuelle Geographien: Zur Produktion, Aneignung und Vermittlung von RaumBildern, edited by: Schlottmann, A. and Miggelbrink, J., Sozial- und Kulturgeographie, 2, transcript Verlag, Bielefeld, 31-47, 201.

Hasse, J.: Urbane Atmosphären der Natur, in: Die Experimentalstadt, edited by: Reinermann, J.-L. and Behr, F., Springer Fachmedien Wiesbaden, Wiesbaden, 41-58, 2017.

Hellriegel, J. and Čubela, D.: Das Potenzial von Virtual Reality für den schulischen Unterricht: Eine konstruktivistische Sicht, MedienPädagogik, 2018, 58-80, https://doi.org/10.21240/mpaed/00/2018.12.11.X, 2018.

Hubbard, P.: City, Second Edition, Routledge, London, New York, 2018.

Kazig, R.: Atmosphären. Konzept für einen nicht repräsentationellen Zugang zu Raum, in: Kulturelle Geographien nach dem Cultural Turn, edited by: Berndt, C. and Pütz, R., transcript Verlag, Bielefeld, 167-187, 2007. 
Kerz, C.: Atmosphäre und Authentizität: Gestaltung und Wahrnehmung in Colonial Williamsburg, Virgina (USA), Erdkundliches Wissen, 161, Franz Steiner Verlag, Stuttgart, 2017.

Luhmann, N.: Soziale Systeme: Grundriß einer allgemeinen Theorie, suhrkamp taschenbuch wissenschaft, Frankfurt am Main, 1984.

Machin, D.: Introduction, in: Handbooks of Communication Science [HoCS]: 4: Visual Communication, edited by: Machin, D., De Gruyter, Berlin, 2014.

Manemann, J.: Kritik des Anthropozäns: Plädoyer für eine neue Humanökologie, X-Texte zu Kultur und Gesellschaft, transcript Verlag, Bielefeld, 141 pp., 2014.

Mohring, K. and Brendel, N.: Vom Ort zur virtuellen Welt Studierende designen in Wien eine VR-Exkursion zu nachhaltiger Stadtentwicklung, in: Exkursionen und Exkursionsdidaktik in der Hochschullehre, edited by: Seckelmann, A. and Hof, A., Springer Verlag, Berlin, Heidelberg, 129-148, 2020.

Nöthen, E. and Schlottmann, A.: "Stadt in den Blick genommen" - Ansätze zur Differenzierung beim Erwerb kritisch-reflexiver visueller Kompetenz, GW-Unterricht, 139, 32-41, 2015.

Rink, D. and Haase, A. (Eds.): Handbuch Stadtkonzepte, Barbara Budrich, Opladen, Toronto, 2018.

Rosa, H.: Resonanz. Eine Soziologie der Weltbeziehung, Suhrkamp, Berlin, 2016.

Sanchez-Vives, M. V. and Slater, M.: From presence to consciousness through virtual reality, Nat. Rev. Neurosci., 6, 332-339, https://doi.org/10.1038/nrn1651, 2005.

Sanders, C.: Degrowth-Politik, Resonanz und mentale Infrastrukturen, in: Postwachstumspolitiken: Wege zur wachstumsunabhängigen Gesellschaft, edited by: Adler, F. and Schachtschneider, U., Oekom, München, 2017.

Schlottmann, A. and Miggelbrink, J.: 1. Ausgangspunkte: Das Visuelle in der Geographie und ihrer Vermittlung, in: Visuelle Geographien: Zur Produktion, Aneignung und Vermittlung von RaumBildern, edited by: Schlottmann, A. and Miggelbrink, J., Sozial- und Kulturgeographie, 2, transcript Verlag, Bielefeld, 1330, 2015a.

Schlottmann, A. and Miggelbrink, J. (Eds.): Visuelle Geographien: Zur Produktion, Aneignung und Vermittlung von RaumBildern, Sozial- und Kulturgeographie, 2, transcript Verlag, Bielefeld, 2015b.

Schöne, B., Wessels, M., and Gruber, T.: Experiences in Virtual Reality: a Window to Autobiographical Memory, Curr. Psychol., 38, 715-719, https://doi.org/10.1007/s12144-017-9648-y, 2019.

Schuller, W.: "Evolution Takes Love": Tracing Some Themes of the Solarpunk Genre, available at: https://qspace.library. queensu.ca/bitstream/handle/1974/26518/Schuller_William_ K_201909_MA.pdf?sequence $=2$ \&isAllowed $=y$ (last access: 10 August 2021), 2019.

Schulze, U., Kanwischer, D., Gryl, I., and Budtke, A.: Mündigkeit und digitale Geomedien - Implementation eines digitalen Fachkonzeptes in der geographischen Lehrkräftebildung, AGIT - Journal für Angewandte Geoinformatik, 6, 114-123, https://doi.org/10.14627/537698011, 2020.
Schurr, C. and Strüver, A.: "The Rest": Geographien des Alltäglichen zwischen Affekt, Emotion und Repräsentation, Geogr. Helv., 71, 87-97, https://doi.org/10.5194/gh-71-87-2016, 2016.

Seaford, C.: Is Wellbeing a Useful Concept for Progressives?, in: The Politics of Wellbeing: Theory, Policy and Practice, edited by: Bache, I. and Scott, K., Wellbeing in Politics and Policy, Springer International Publishing, Cham, 97-120, 2018.

Seinfeld, S., Arroyo-Palacios, J., Iruretagoyena, G., Hortensius, R., Zapata, L. E., Borland, D., Gelder, B. de, Slater, M., and Sanchez-Vives, M. V.: Offenders become the victim in virtual reality: impact of changing perspective in domestic violence, Sci. Rep., 8, 2692, https://doi.org/10.1038/s41598-018-19987-7, 2018.

Sieudiver: [Uplifting/Melodic/Trance] Sieudiver - Solarpunk City: available at: https://www.youtube.com/watch?v= bhKEZAlYcME (last access: 10 August 2021), 2016.

Slater, M.: Place illusion and plausibility can lead to realistic behaviour in immersive virtual environments, Philos. T. R. Soc. B, 364, 3549-3557, https://doi.org/10.1098/rstb.2009.0138, 2009.

Slater, M. and Sanchez-Vives, M. V.: Enhancing Our Lives with Immersive Virtual Reality, Front. Robot. AI, 3, 74, https://doi.org/10.3389/frobt.2016.00074, 2016.

Slater, M. and Wilbur, S.: A Framework for Immersive Virtual Environments (FIVE): Speculations on the Role of Presence in Virtual Environments, Presence: Virtual and Augmented Reality, 6, 603-616, https://doi.org/10.1162/pres.1997.6.6.603, 1997.

Southgate, E., Smith, S. P., Cividino, C., Saxby, S., Kilham, J., Eather, G., Scevak, J., Summerville, D., Buchanan, R., and Bergin, C.: Embedding immersive virtual reality in classrooms: Ethical, organisational and educational lessons in bridging research and practice, International Journal of Child-Computer Interaction, 19, 19-29, https://doi.org/10.1016/j.ijcci.2018.10.002, 2019.

Spangeberg, P. M.: Komplexitätsebenen moderner Öffentlichkeit. Über die mediale Emergenz kommunikativer Wirklichkeitskonstruktion und ihre Verfremdung durch technische Visualisierung, in: Medien und Öffentlichkeit. Positionierung, Symptome, Simulationsbrüche, edited by: Maresch, R., Boer, München, 263-277, 1996.

Stalder, F.: Herausforderungen der Digitalität jenseits der Technologie, Synergie - Fachmagazin für Digitalisierung in der Lehre, 5, 8-15, 2018.

Strüver, A.: Körper, in: Handbuch kritische Stadtgeographie, 4. Auflage, edited by: Belina, B., Naumann, M., and Strüver, A., Verlag Westfälisches Dampfboot, Münster, 285-290, 2020.

WDR: Berlin Terror - die ersten Helfer vom Breitscheidplatz in $360^{\circ} / \mathrm{VR}$, available at: https://www.youtube.com/watch?v= kzPVywVFMZA\&feature=youtube (last access: 14 February 2021), 2017. 